\title{
ELIA ESPINOSA
}

\section{La obra de Becky Guttin Escultura de oposiciones}

I.

L A ESCULTURA MEXICANA (joven-madura) se define por su diversidad en los temas, los materiales, soluciones técnicas, metodológicas y artísticas que, obviamente, pertenecen al reino de la generación y consolidación de signos escultóricos.

La escultura mexicana es excepcionalmente experimentadora y ha cosechado frutos significativos en el terreno de la abstracción geométrica, en las formas blandas (irregularidad de la no forma) y en el realismo figurativo. Se caracteriza por la variedad en la búsqueda de materiales, las incursiones en la interioridad del artista como fuente de renovación de sus contenidos y metodologías, además de las soluciones propias a sus códigos con nuevas proyecciones estéticas. A tal espectro de riqueza técnica conceptual y estética se aúna el que la escultura en general, a bien decir de Juan Acha, es un arte que se salva de cualquier sectarización o individualismo cerrado: "Por fortuna, los escultores no son proclives, como los pintores, a tener por creación artística la autoexpresión narcisista o la reproducción de realidades visibles. Buscan más allá del egocentrismo y de la mímesis. Abdican de la semántica y se abocan con las sintaxis volumétricas de belleza formal, que corresponden a la dimensión estructural de la escultura." De este juicio es posible deducir que esas características propias, diríamos "connaturales" de la escultura, la mantienen en un ancho margen de posibilidades de rejuvenecer.

I. Juan Acha, "Las dificultades del escultor", en 3 dimensiones, 20 expresiones, catálogo de exposición, México, Musco de Arte Moderno, julio-agosto, 1988, s.n., ils. 
Esos procesos de incesante renovación se refuerzan por una tradición escultótica que va desde la piedra al acrílico, y desde las masas monumentales prehispánicas hasta las esculturas transitables (Goeritz y Silva, por ejemplo).

La tradición de la escultura mexicana está al alcance de los escultores actuales que, incipientes o ya maduros en su oficio y lenguaje, no pueden sustraerse a su influjo.

Escultora que transfigura la materia con un lenguaje ya propio, Becky Guttin ha recorrido no pocos caminos de búsqueda y enfrentado arduos problemas propios de su oficio. Lo que más atrae, conmueve, invoca a primera vista a la indagación, a la valoración estética de las esculturas de esta autora es su vigorosa, al mismo tiempo que delicada, elaboración de espacios y antiespacios. Su punto de partida es la oposición de materiales, conceptos, sensaciones, texturas abruptas o superficies reflejantes.

La oposición, los vacíos en sintaxis contradictorias, la texturación, ${ }^{2}$ las apariencias y la variedad de materiales, son los elementos de concepción y los métodos que determinan, a grandes rasgos, los resultados estructurales y propiamente sígnicos, generales o específicos, de cada obra que realiza la artista.

El equilibrio múltiple que se genera y entreteje con las estructuras de sus obras proviene de una constante asimetría transgresora de la estabilidad y lo que podría llamarse una asfixia espacial (generación de antiespacios), tensión pura, acompañada de la multiplicidad informal que la alimenta.

Tras una veloz mirada a la producción de Guttin, es notable que la autora no siempre se interesa por los volúmenes en sí. Se avoca al sentido y las formas nuevas en constante deconstrucción y fluyendo al ritmo de una texturación profunda.

Una red vectorial sostiene el universo de su escultura. De esa red dependen, y ahí convergen, las oposiciones y el equilibrio de tensiones fun-

2. La palabra "texturación" no existe en español, pero ha sido necesario crearla para dar un nombre a la acción de hacer texturas e incidir en ellas, dándoles un nivel importante en la obra. En Becky Guttin, lo veremos, hay texturación y texturalidad. Esta última es una de las cualidades principales de su trabajo. 
damentadas en concavidades encontradas, horizontales y verticales, cruces de diagonales, perpendiculares con la vertical ascendente o descendente, horizontales o diagonales que contrafuerzan una vertical sobre el plano, espirales que suben, líneas quebradas y curvas que despliegan su amplitud y regresan al horizonte del que surgieron. ${ }^{3}$

Los vectores que determinan la composición y estructura de las obras considetadas ascienden a gran número y forman tejidos de direcciones muy complejas. Se ofrecen enseguida doce esquemas de los vectores elementales que arman la composición:
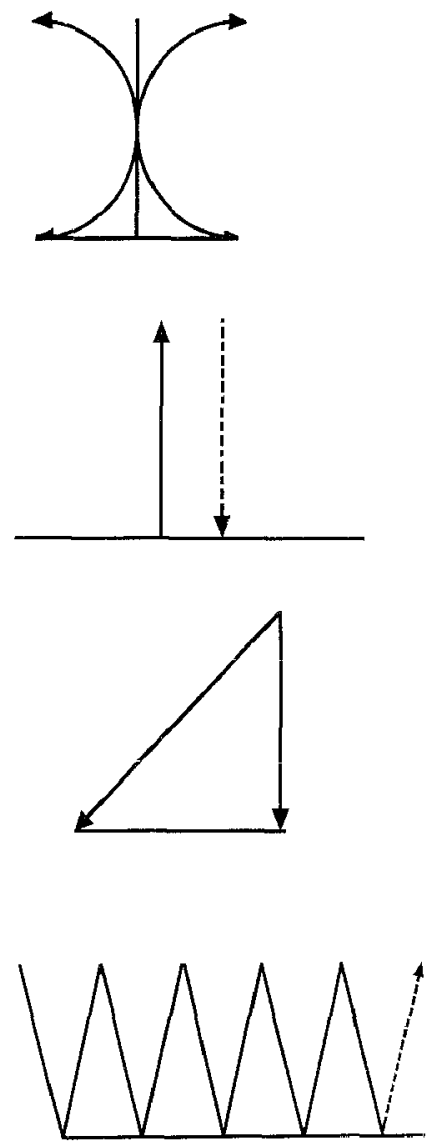
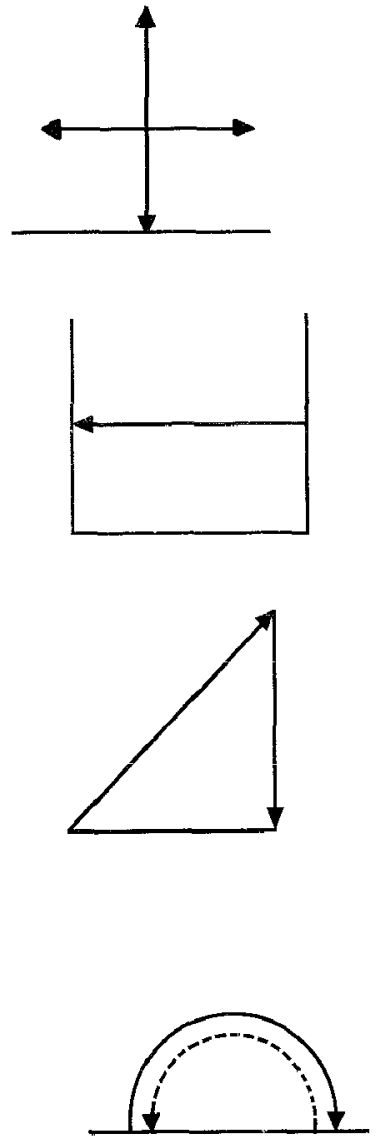
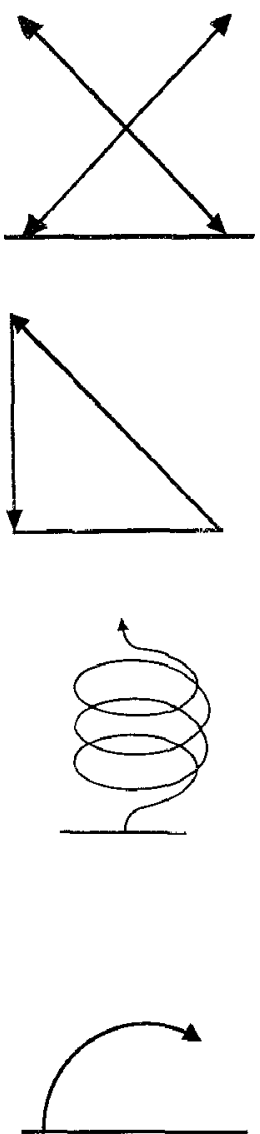

3. En todas las artes plásticas, escénicas, la literatura, la música, etcétera, la existencia de vectotes es medulat. Señalatlos es imprescindible para apreciar mejor la totalidad de concepción y de tealización de las obras y el origen de su madurez sígnica y técnica. 
IOO

Un grupo de esculturas elaboradas entre 1989 y 1992 fueron construidas con algunos de estos vectores. Durante ese periodo, Guttin incidió en algunas constantes recurrentes que le han conformado un estilo experimental: esferas rotas; cuadrados de bronce o vidrio atravesados por cuerpos del mismo material; pequeñas bóvedas de bronce de diversos espesores, con oquedades en su superficie; pirámides o triángulos metálicos en composiciones sugetentes; láminas y hojas de bronce informes, cual vestigios orgánicos que circunvolucionaran en oposiciones de espirales y diagonales, o en composiciones, por adición o sustracción, de elementos en sentido zigzagueante (juego de diagonales); grandes láminas de cobre que desgajan el espacio y convergen en un centro único, abriendo y cerrando espacios y antiespacios; troncos hendidos por hojas de vidrio afiladas, o estratificaciones de madera $y$ plomo en donde lo más importante son las texturas. Y suma y sigue. Éstos son los recursos que pueblan la imaginación escultórica de Becky Guttin, quien afirma: "el salto de un material a otro enriquece los métodos para regresar a los materiales iniciales o a nuevos por conocer." 4

No es posible detener el análisis en algunas obras específicas sin reiterar que la investigación de materiales, los conceptos y los raptos instintivos modulados por esa investigación, son punto de arranque y motivación medulares en la artista. Es imprescindible señalar que mediante los nombres dados a cada obra, un sugestivo conjunto de significados (escritura-imagen-sensación) coadyuvan en todos sentidos a acrecentar la fuerza de su producción.

Se distinguen seis grupos diferentes de esculturas en la producción de la artista. Esos grupos acogen nuevas obras que ella va produciendo, con grados de fuerza y resolución diferentes en el manejo de las oposiciones (tensión, distensión), el orden de la materia, las texturas, el color y su intensidad. Hay que partir del análisis de la conducción de esas dimensiones para obtener elementos que permitan conceptualizar para poder hablat de la compleja estética y consecuencias poéticas de la obra de Guttin.

I. En el primer grupo, la oposición está marcada drásticamente por el encuentro-desencuentro de materias y de prismas con formas y extensiones

4. Conversación con Becky Guttin, México, febrero de 1993.

5. Esta división es una herramienta metodológica para profundizar en los valores estéticos de la obra. Es evidente que aquella puede ser apreciada desde otros puntos de vista. Si se observa la obra de Guttin con los criterios esquemáticos que propongo, se advierte, incluso, que entre esos grupos hay una importante telación con la estructura. 


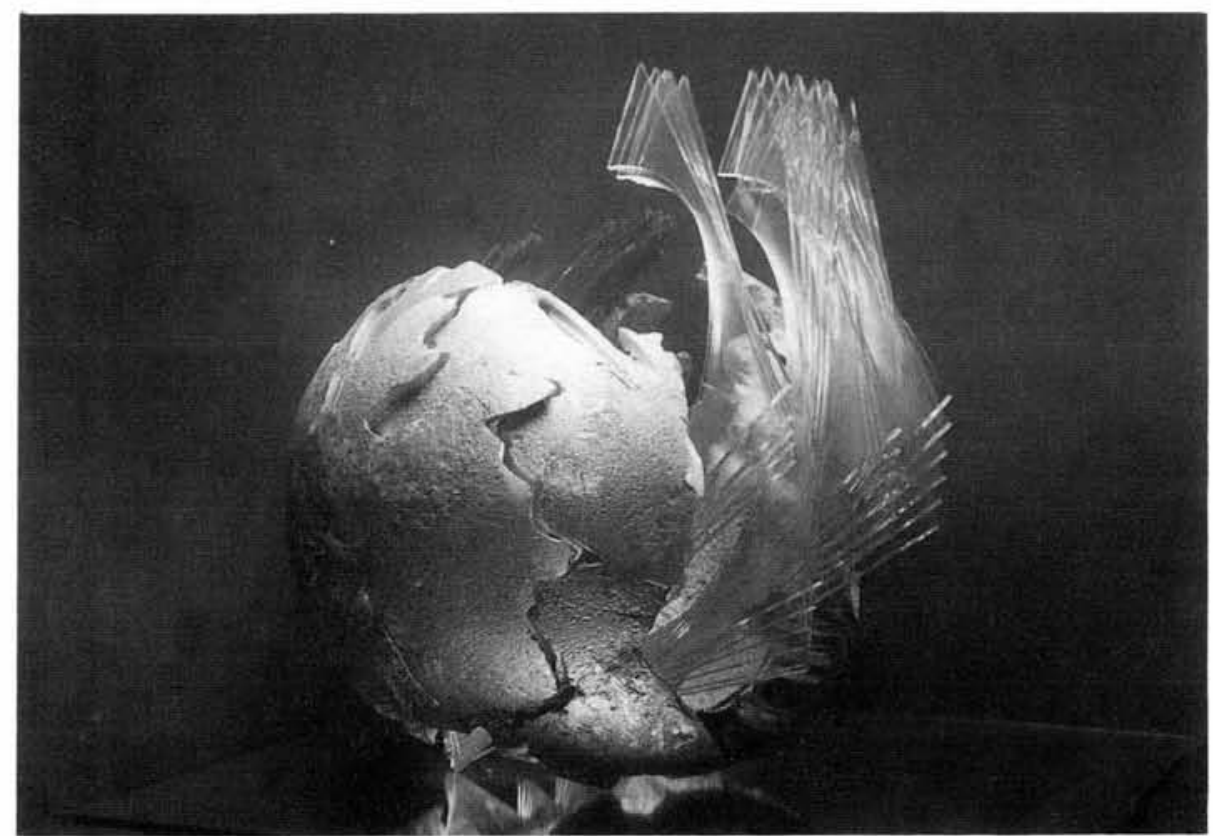

Figura I. Becky Guttin, Ciclos, 1990. Aluminio y hojas de vidrio, 6I x 49.5 x $51 \mathrm{~cm}$. Foto: Ernesto Álvarez.

puramente plásticas, evocadoras, sin embargo, de lo orgánico. Algunos materiales son de gran espesor y tienden al verde (la pátina del bronce y las gruesas placas de vidrio, a contraluz y de canto), al negro, al gris aluminio, a los ocres y a los tonos lejanamente violáceos. Las texturas son determinantes, pero más lo son las oposiciones.

Ejemplos de este grupo serían Ciclos (1990; figura I), Marcos temporales (1990; figura 2) y Silencio urbano I (1991; figura 3), entre otros.

Ciclos opone el "alma" de una esfera y la de un cuadrado: una esfera de aluminio trabajada en estratos sobrepuestos y formas orgánicas es "herida" por cuadrados de hoja de vidrio muy fina, afilada, desafiante. Los marcos de vidrio se suceden en serie, creando un movimiento horizontal y ascendente simultáneo. Se superponen sugestivamente a la oposición de la fría y brillante superficie del vidrio y la escarpada hostilidad del aluminio.

La complejidad vectorial de Ciclos es infinita en convergencia y divergencia. La esfera metálica escapa a esa complejidad por su propia naturaleza, pero en torno a ella se organiza la fina colocación de lajas de vidrio que tienden a subir en abanico. Los vectores fundamentales de esa escultura son dos diagonales que controlan el despliegue de las que surgen los vidrios y su 


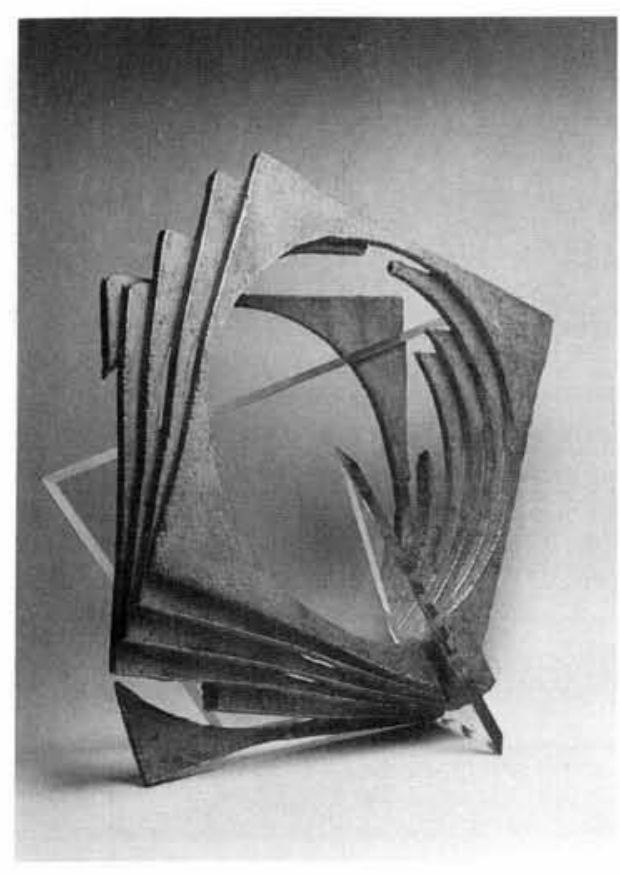

Figura 2. Becky Guttin, Marcos temporales, 1990. Bronce y vidrio, 50 × 61 x $30 \mathrm{~cm}$. Foto: Becky Guttin (en adelante B.G.).

movimiento: la que parte de la base de la escultura, ascendiendo hacia la derecha, y aquella que, formando un triángulo con la primera, sube ligeramente hacia la izquierda.

Oposición de gran elegancia formal y riqueza de sentidos de las partes que la constituyen (bronce, vidrio), Marcos temporales representa un buen ejemplo de las búsquedas espaciales de Becky Guttin. Cuadrados de bronce patinado con verde se despliegan como un abanico de naipes, mientras en el vértice inferior derecho, un triángulo tenaz y certero los sujeta apuntando en contrasentido. Marcos temporales posee un decidido movimiento de forma y opone con sobriedad lo liso y la traslucidez a lo rugoso. Sin embargo, su equilibrio se resuelve en aparentes desbalances.

La red vectorial de Marcos temporales nace de un sustancioso juego de cuadrados y triángulos dispuestos en movimiento de despliegue. El triángulo de vidrio recoge, amarra y concentra el punto de apoyo del conjunto general. Va en sentido ascendente hacia la izquierda, oponiéndose a la dirección de los cuadrados de metal (algunos enteros, otros cortados), "clavados" en la base, por su vértice inferior derecho. Los lados de los cuadrados, uno sobre el otro en abanico, los lados y bases de los triángulos de grueso vidrio, colocados como están, propician una fuga de líneas y, por tanto, de espacios abier- 


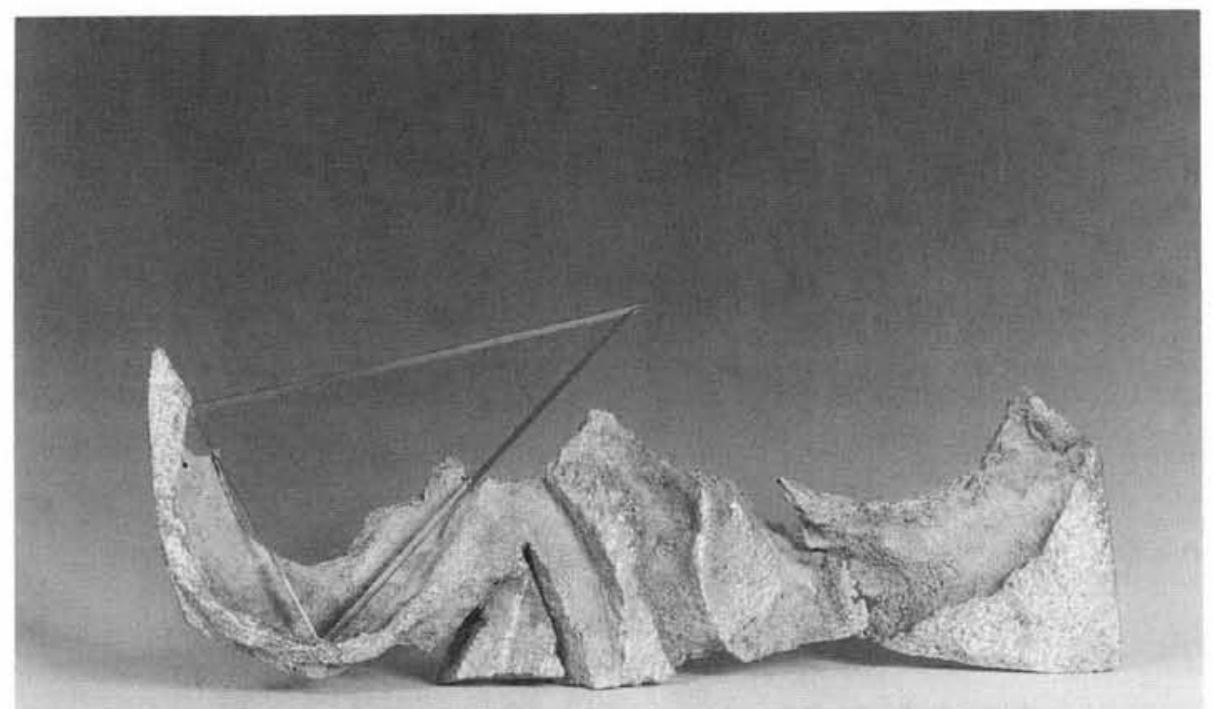

Figura 3. Becky Guttin, Silencio urbano I, 1991. Bronce y vidrio, 19 x 54 x $20 \mathrm{~cm}$. Foto: B.G.

tos al infinito. El recurso de los círculos vacíos dentro de los cuadrados, en ruptura sucesiva, sugiere una alternancia de bien resueltas tensiones.

La riqueza vectorial de Silencio urbano I es muy sutil. Pedazos de bronce ocre claro se conjuntan con un ritmo de olas, concavidades y convexidades rugosas, casi superficies pétreas. Un triángulo de vidrio transparente transgrede ese ritmo. Se dispara de izquierda a derecha, en diagonal ascendente, pero la quietud y suavidad que evoca (de nuevo por oposición) da una delicada coherencia a esa pieza.

No obstante la numerosa gama de vectores que podríamos señalar en la parte de bronce de esta escultura (varias diagonales ascendiendo hacia la izquierda, cuatro a la derecha), en ella impera la horizontalidad. Sin embargo, el triángulo isósceles de vidrio, cortante, clavado en el extremo izquierdo, determina la tensión vectorial más enérgica del conjunto: hunde su vértice inferior derecho, en actitud de hacha. Al mismo tiempo, de ese vértice surgen su base y uno de sus lados como dos vectores que divergen al infinito. De su vértice superior brotan otras dos diagonales abiertas, que descienden también en términos de nunca converger. Si se continúan esas dos diagonales después de rebasar el vértice en el que se unen, veremos que trazan otro invi- 


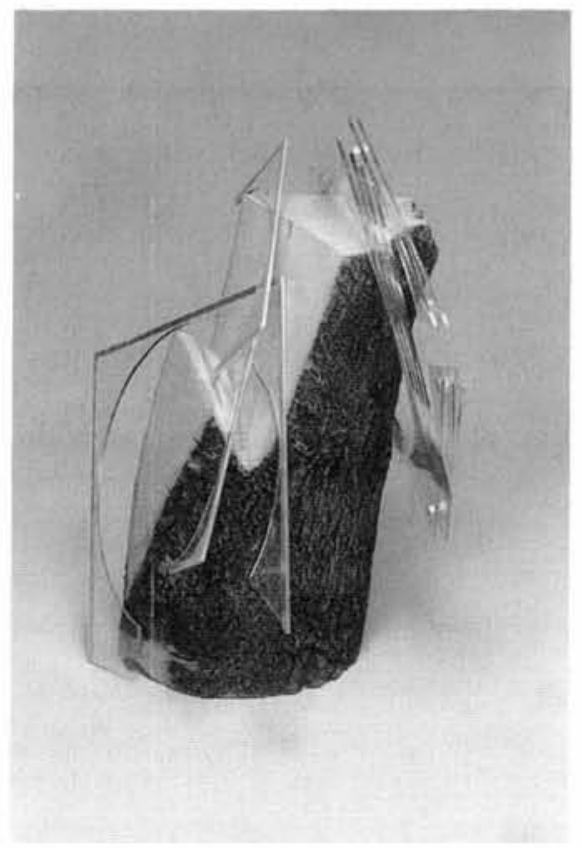

Figura 4. Becky Guttin, Silencio urbano II, 1990. Madera y vidrio, 64.7 x $6 \mathrm{I}$ x $50 \mathrm{~cm}$. Foto: Jesús Sánchez Uribe (en adelante J.S.U.).

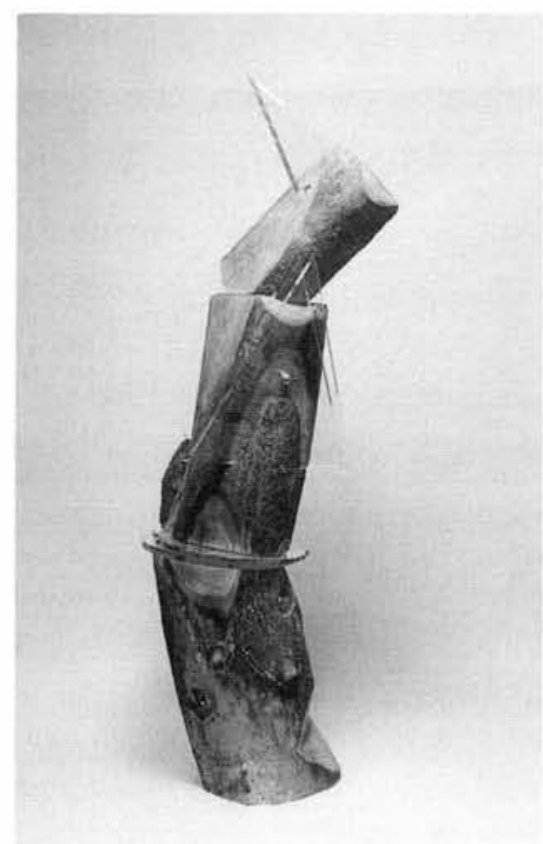

Figura 5. Becky Guttin, Silencio urbano III, 1991. Madera y vidrio, $142 \times 66 \times 56$ $\mathrm{cm}$. Foto: Jorge Vértiz (en adelante J.V.).

sible triángulo que se esfuma en el espacio. En este primer grupo, Guttin emplea el color como evocador y como refuerzo de tensiones.

2. El segundo grupo de esculturas lleva a un grado extremo la fuerza e intensidad de la oposición de materiales. Hace trascender, mucho más que el grupo anterior, la definición y energía de una realidad: las sensaciones duales profundas, es decir, aquellas que son experimentadas en la totalidad de nuestro ser, pero son "vistas" con el tacto y "tocadas" con la mirada. Son ópticamente táctiles y táctilmente ópticas. La profunda sensación de cortadura que producen las esculturas de madera y vidrio de Guttin son un claro ejemplo; al contemplarlas no sabemos si la cortadura es primero en la retina o en el tacto.

En esas obras, las texturas perfilan mucho más la esencia de los materiales. La madera, el vidrio, y sus propiedades: la maleabilidad y la calidez frente a la tenacidad y la frialdad.

El reino textural de bordes afilados constituye un acierto no sólo escultórico y de perspectiva, sino de conocimiento de las posibilidades de la materia, verdadera constante en el universo de la artista. 


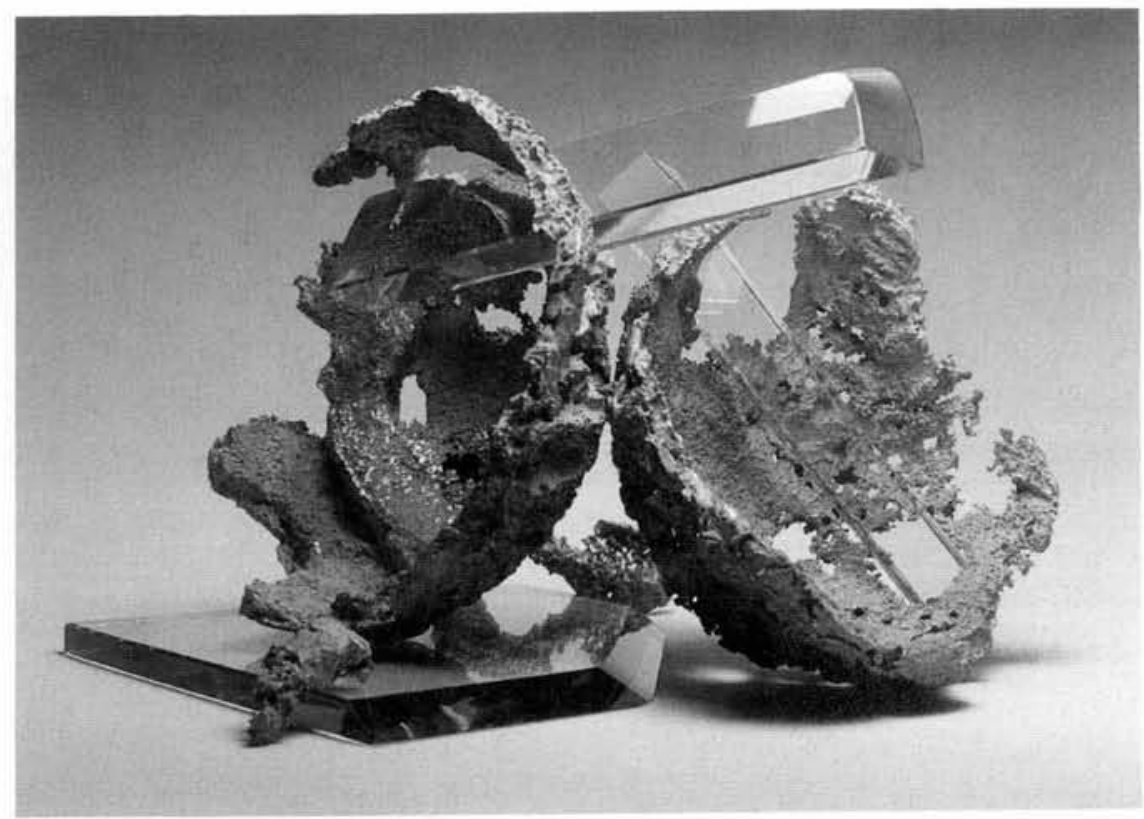

Figura 6. Becky Guttin, Desmembramiento formal, 1990. Bronce y vidrio, 50 x $63.5 \times 40.5$ $\mathrm{cm}$. Foto: Gabriel Figueroa (en adelante G.F.).

Silencio urbano II (1990; figura 4) y Silencio urbano III (I99I; figura 5) denotan la conducción manual ya muy entrenada de esos encuentros matéricos tan singulares. Modifican agudamente el espacio creando otros espacios cual navajas que se hundieran en carne invisible, con sutiles zigzagueos esbozados ilusoriamente por la inserción o colgadura de hojas de cristal en los troncos previamente facetados. En su continuidad de separaciones, cortaduras y aparente calma, hay una mayor transformación del espacio circundante que la alteración espacial que implican en sí como esculturas.

La hiriente atracción visual que esas esculturas ejercen en el espectador las convierten en piezas únicas de la producción de Guttin. Tienen la capacidad de propiciar con eficaz elementalidad sensaciones táctiles en el espectador.

3. Desmembramiento formal (1990; figura 6), Encaje celeste (I99I; figura 7) y Pietra santa (1991; figura 8), tercer conjunto de esculturas, están formadas por oposiciones de materiales y espesores, pero las formas, la intención que las anima, los sentidos que esparcen en su derredor, son una secuencia fluida parecida al contrapunto.

Becky Guttin trabaja en esas obras utilizando espesores delgados en el bronce. Degrada los bordes de las láminas con irregularidades de fragmento 


\section{6}

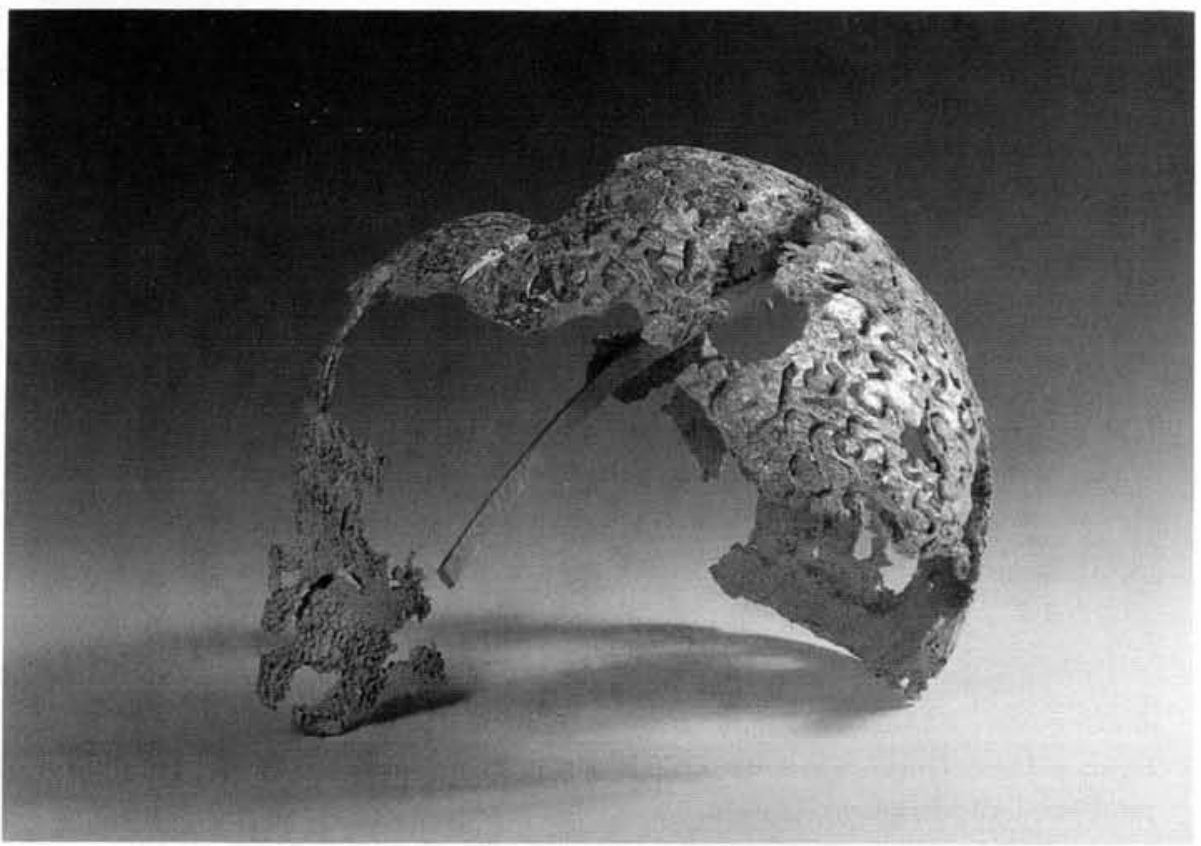

Figura 7. Becky Guttin, Encaje celeste, 1991. Bronce, 30 x 40 x $38 \mathrm{~cm}$. Foto: G.F.

de tierra en un mapa (recuerdan el hierro oxidado, devastado por la corrosión) y les prodiga formas semiesféricas y ovoidales (como cáscaras) pobladas de agujeros, pliegues y diminutas cordilleras con las que acostumbra invadir las superficies.

Las rugosidades, recurso esencial en la expresión plástica de Guttin, terreno abrupto, irremediablemente evocador de caparazones y piedras marinas, en contraste con las gruesas planchas de vidrio tenuemente esmeraldino, brillante, transparente, constituyen hallazgos de doble naturaleza. Por un lado, denotan un dominio en la tarea a la vez cotidiana y extraordinaria de tocar, sentir y saber hacia dónde transmutar lo palpado y sentido. Por el otro, llevan las sensaciones de repulsión, asombro y extrañeza que nos invadieron al percibirlas, mucho más allá de las formas inmediatas que nos circundan.

Desmembramiento formal es la pieza que presenta con mayor decisión ese continuo — solicitamos el término a la técnica musical— de formas que se oponen por su posición o sólo por sus materiales. Dos medias esferas verdeazules degradadas con horadaciones y oquedades del tiempo se sitúan, casi diametralmente opuestas, una sobre base de vidrio reflejante; la otra, sobre una mesa. Los dos elementos oponen sus igualdades diversas. Unen sus con- 


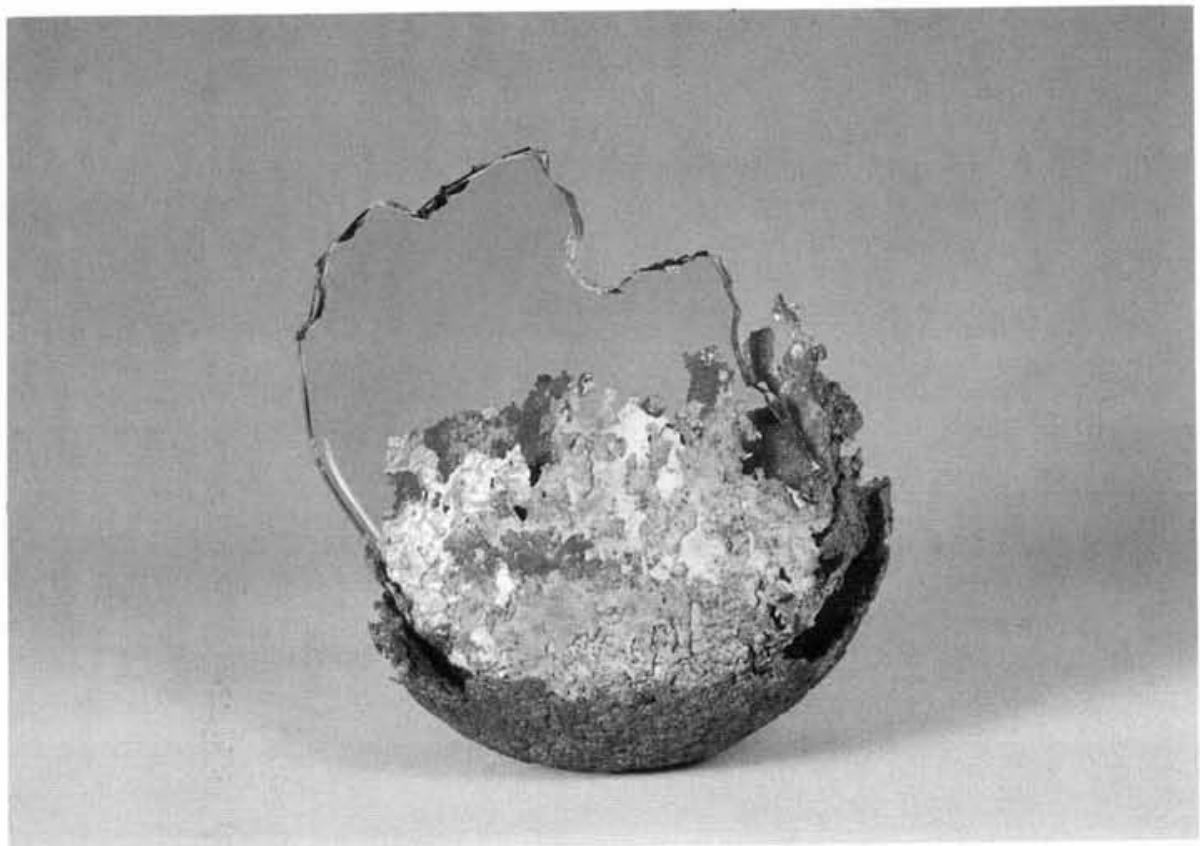

Figura 8. Becky Guttin, Pietra santa, 199I. Alpaca, aluminio y vidrio, $40 \times 35 \times 20 \mathrm{~cm}$. Foto: J.V.

vexidades al mismo tiempo que son atravesadas —encuentro basado en el contraste - por gruesas barras de vidrio en sentido diagonal postero-anterior y diagonal ascendente desde el ángulo inferior derecho. Los vectores que genera esta fuerte y bien estructurada composición son numerosos, además del uso del reflejo en la base, que multiplica la zona inferior del conjunto hacia abajo. En otras obras esa intención es mucho más definida gracias al uso del espejo. Desmembramiento es un excelente ejemplo de armonía formal lograda por oposición.

No está de más insistir en que el tramado vectorial de esa pieza es de los más complicados de la producción de Guttin. Su estructura virtual está compuesta por nueve líneas principales sin cuyo decidido disparo, a veces el de una flecha, no habría respaldo suficiente para el contraste que alcanzan las texturas tan diversas de la obra.

En Encaje celeste, el "espíritu" de una media esfera trae a la memoria la imagen de un cráneo fosilizado. A su muy sustanciosa texturalidad se aúna el delicado contraste que nace de la inserción de dos varillas planas en su interior, hecho que confirma el mundo de oposiciones en el que se gestan y concretan las obras de Guttin y la simbiosis de alteraciones que establecen con el espacio. 


\section{I08}

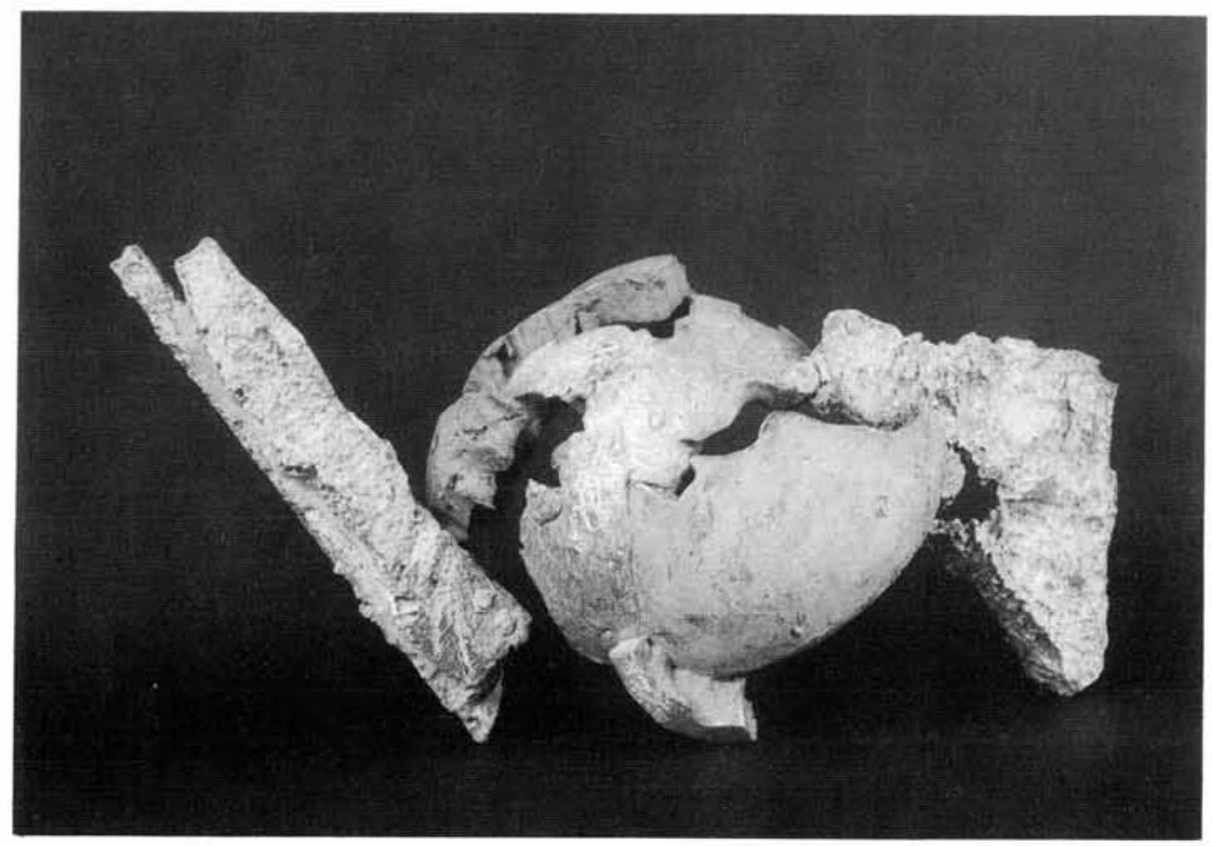

Figura 9. Becky Guttin, Tiempo y balance, 1991. Bronce, 35 x 71 x $35 \mathrm{~cm}$. Foto: G.F.

Encaje celeste y Pietra santa están entonadas en ocres claros, pardos y verdes terrosos, luminosos y fríos, matices que aminoran visualmente las tensiones.

Pietra santa es especial por sus cualidades. Su juego de formas lógico y natural, sus espesores y perfiles irregulares, su acoplamiento de materiales diferentes (vidrio, aluminio y alpaca) le otorgan un apogeo y armonía elementales. La escultora resolvió allí un acoplamiento de esencias, no de formas opuestas. El vidrio nace del receptáculo (¿una cáscara, una membrana reseca?), base y sostén de su totalidad. Pietra santa es uno de los trabajos sencillos y acertados de la autora

4. Un cuarto conjunto lo forman piezas en las que la oposición radica en las formas y el color, no en los materiales que conforman la estructura ni en las texturas. Tiempo y balance (I99I; figura 9) es un ejemplo evocador de contradicciones formales éuya coherencia y acabado fueron resueltos por los medios tonos verde jade-dorado y un suave tono de arena. Los colores se oponen en composiciones diagonales, o en horizontales en cuya trayectoria se enrosca una espiral. La pieza muestra la habilidad de Guttin para manejar 


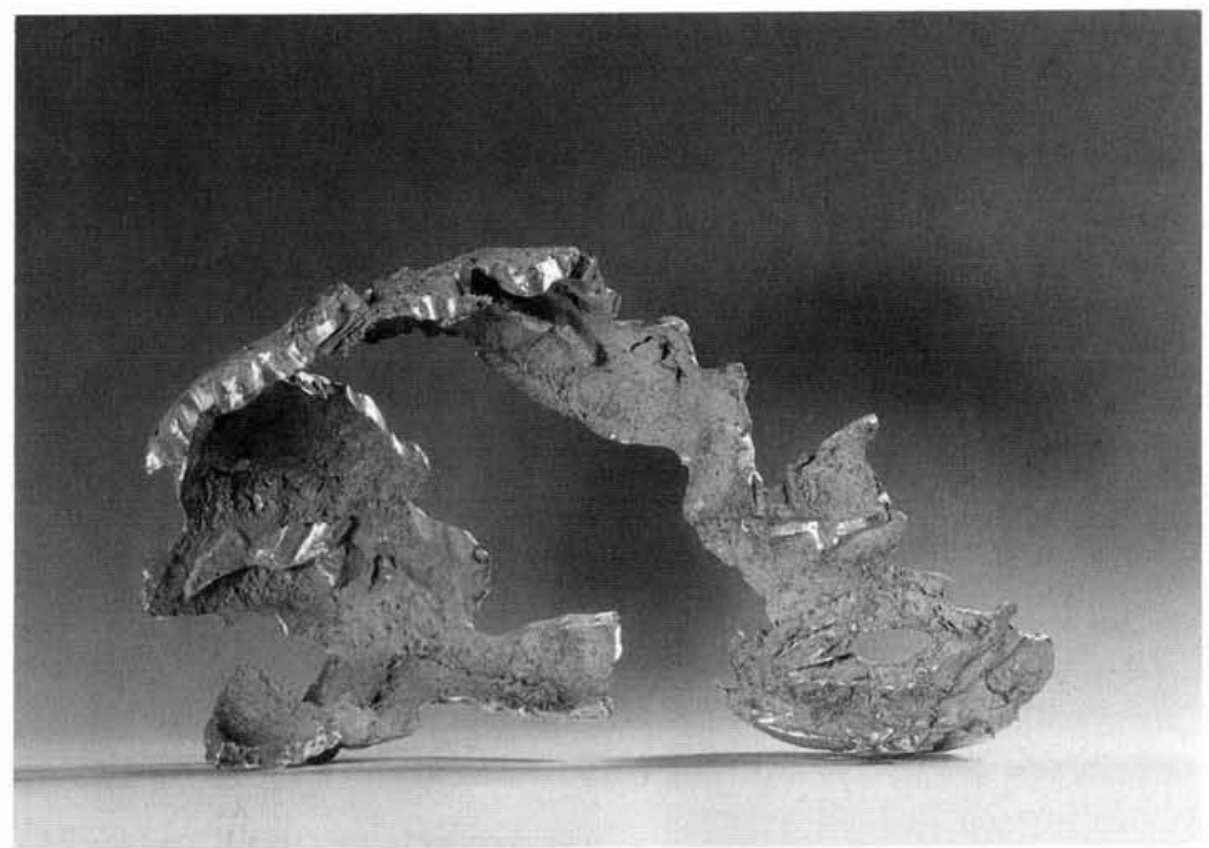

Figura 10. Becky Guttin, Accesos, 1991. Bronce, 30 x 70 x 70 cm. Foto: G.F.

formas y tensiones múltiples con fragmentos de un solo material y notable parquedad cromática.

La sugerente, casi mágica oposición de Accesos (I991; figura I0) radica en su excavación del espacio; umbral en el que texturas bruscas se confunden con el verde y los dorados del bronce pulido. La pieza se inclina hacia la izquierda, con la parte superior doblada hacia delante, como una ceja. La mezcla de intención y azar que constituye esa pieza de vivaz impulso informal, contención y expresividad, se rebela contra la norma. Por sus fervientes texturaciones evoca la apariencia de la piedra o un fragmento de gruta.

5. En otro grupo de obras, Guttin elige el cobre y el aluminio para trabajar a hoja el espacio, sea en maquetas con proyección a lo monumental o en esculturas que miden más de un metro de altura o de largo.

Aún en el camino de las texturas metálicas, pero en una especie de esmerilado, superposiciones de láminas, clavaduras y recortes para crear vanos, Navegando (I99I; figura II) es una búsqueda de interespacios y movimientos de formas muy notables. Las dos láminas mayores, aluminio y cobre, se conforman en un atinado desfase que marca mucho más el movimiento sugerido 


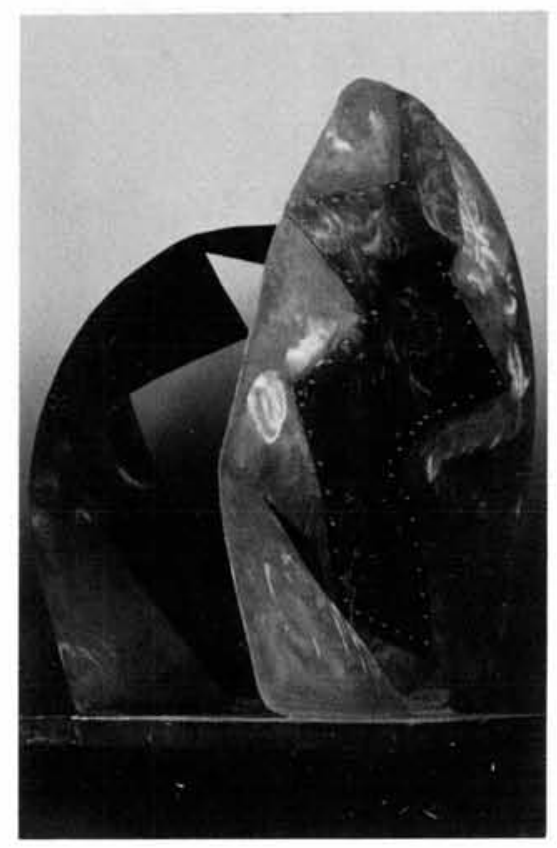

Figura II. Becky Guttin, Navegando, 1991.

Aluminio y cobre, $110 \times 125 \times 85 \mathrm{~cm}$. Foto: B.G.

por el corte de diagonales en el cobre, colocado y remachado, con certeza, sobre el aluminio. A la coherencia, ritmo y equilibrio de composición contribuye la forma semioval o elíptica de los componentes de la escultura, sin excluir la exaltación del brillo y, por lo tanto y más completamente, de la luminosidad que prodigan los reflejos metálicos.

De la misma naturaleza material que la anterior es la maqueta para formato monumental Homenaje a Mathias Goeritz (1991; figura I2). Un largo listón de cobre se desgaja y reintegra en línea quebrada, veloz grafía en el espacio, contracción y distención controladas por un centro único. Nudo invisible del que afluyen los gajos de espacio que se introvierten, extrovierten y gestan bajo el designio de tan sencilla idea.

Es curioso cómo en una pieza que recuerda a Hersua, Becky Guttin se opone absolutamente a los principios circundantes, prismáticos y centrípetos de ese escultor. Mientras la maqueta de la escultora tiene un sentido centrífugo, las obras de Hersua generan su libertad estructural y escultórica en una tensión prismática y autoenvolvente.

6. Una última serie de trabajos (logrados a lo largo de 1993) denota incursio- 
DOI: http://dx.doi.org/10.22201/iie.18703062e.1995.67.1742

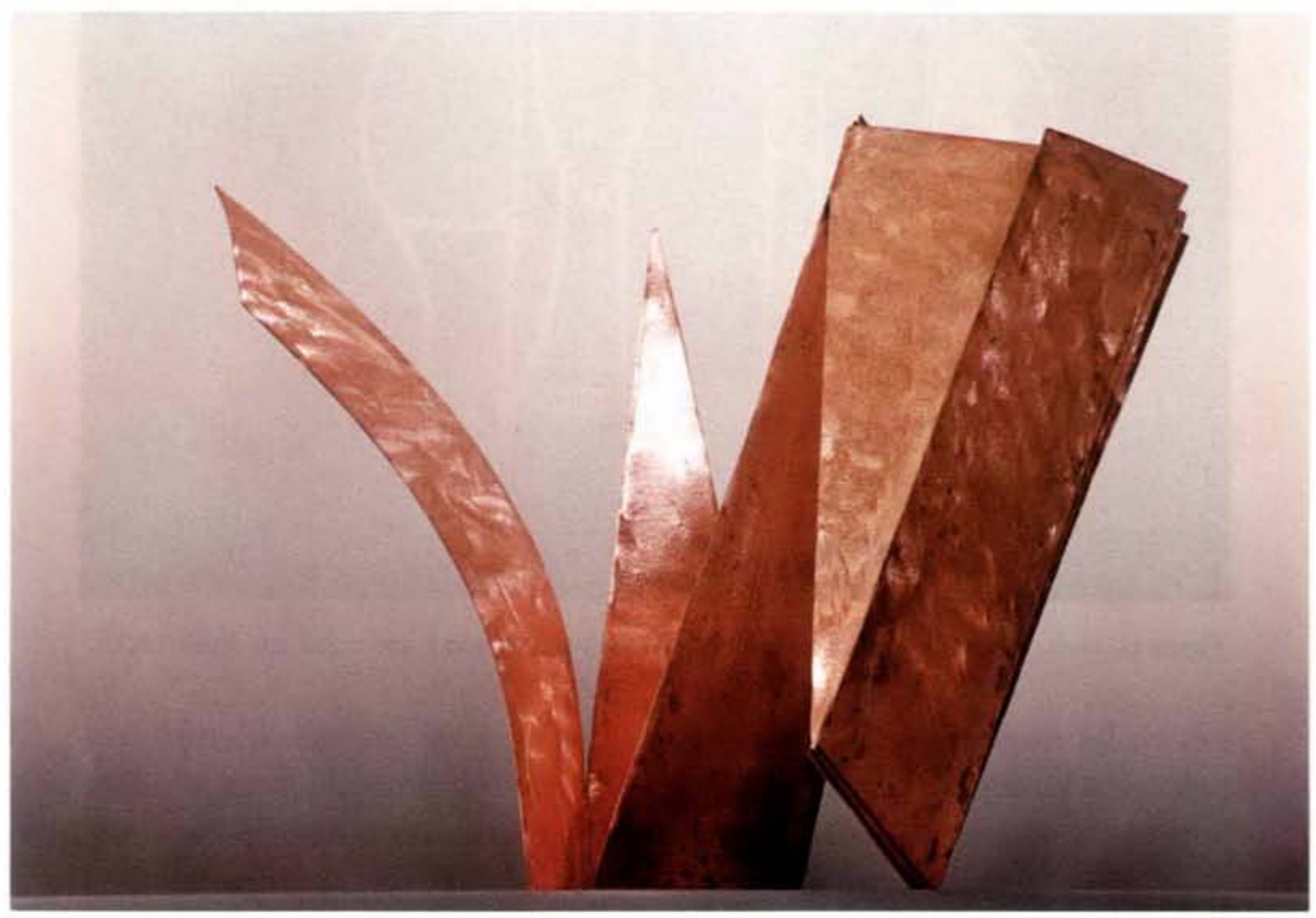

Figura I2. Becky Guttin, Homenaje a Mathias Goeritz (maqueta), 1991. Cobre, 29 x 37 x 35 cm. Foto: B.G. 


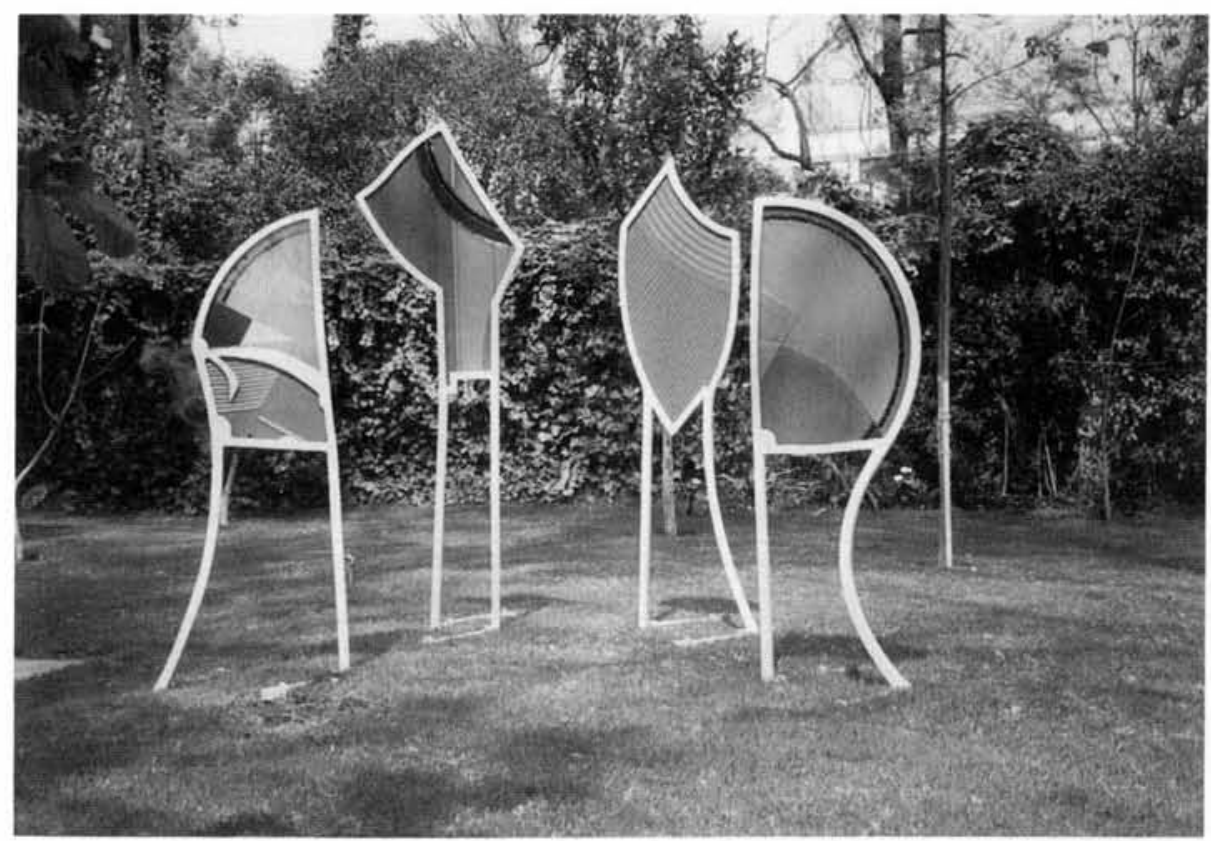

Figura 13. Becky Guttin, Ruido silencioso, 1993. Metal y vidrio, 190 x 200 x 200 cm. Foto: J.S.U.

nes en las nuevas posibilidades sígnicas que el color saturado o deslavado, pero muy luminoso, puede hacer brotar de esas paradojas de metal y vidrio. Son obras en las que esos materiales están trabajados a manera de vitral, Ruido silencioso (figura 13 ), o como pared estriada que se une y contrapone a barras verticales de metal, pintadas de colores vivos, por ejemplo en Conversando de frente (figura 14). Pero la escultora no abandona el apilamiento de delgadas hojas de vidrio, incorporadas equilibrada y serenamente a la totalidad de la estructura metálica que los contiene: como en Homenaje a "El peine del viento" de Chillida (figura I5). Las dimensiones casi monumentales de esas obras oscilan entre I.90 y 2.50 metros de altura, y I.20 y 2 metros de ancho.

La disposición que propicia el sentido coloquial, que insufla la intensión de comunicarse, y los colores que provocan un juego vital de tensiones, que apunta al replanteamiento plástico de los materiales empleados, denotan una nueva vena de investigación y voluntad artístico-moral en la escultora. Súmese a esta tarea escrutadora en el metal, el color y el vidrio, el que Guttin haya realizado así su primer intento, por lo menos declarado y definido, de trabajar la relación entre el espacio-hábitat y el espacio escultórico intrínseco 


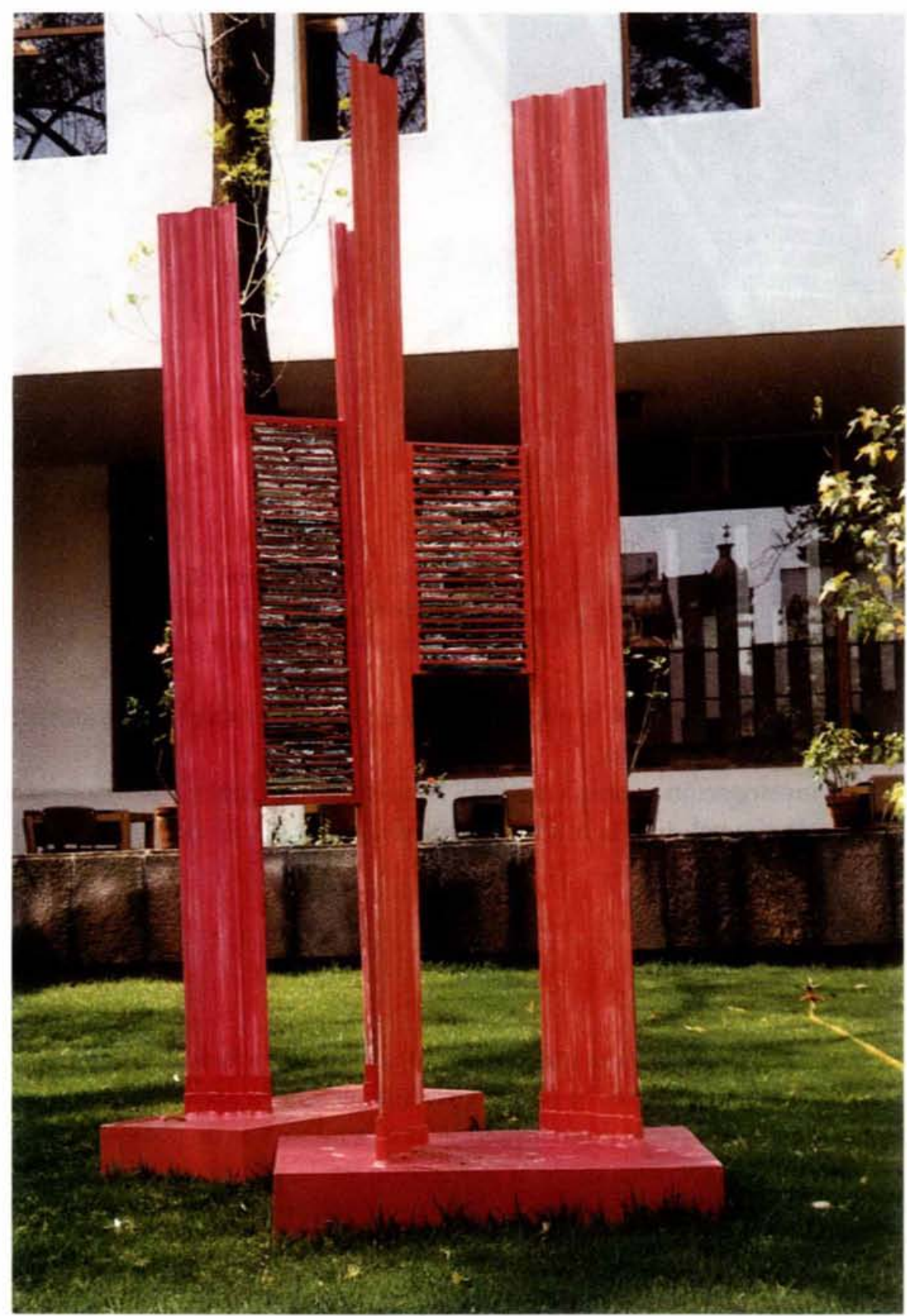

Figura I4. Becky Guttin, Conversando de frente, 1993. Metal y vidrio, $245 \times 95$ x $120 \mathrm{~cm}$. Foto: B.G. 


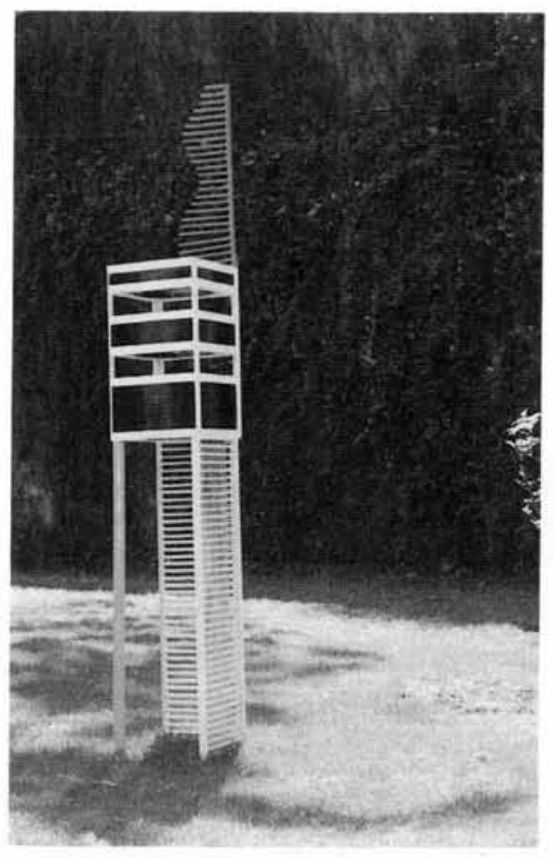

Figura is. Becky Guttin, Homenaje a "El peine del viento" de Chillida, 1993.

Metal y vidrio, $210 \times 35 \times 35 \mathrm{~cm}$. Foto: B.G.

de cada pieza. Columbra la obra teniendo en cuenta el vaivén del escenario en el que serán engarzadas.

Esa investigación propicia no sólo la apertura de espacios particulares a un espacio general, sino la multiplicación del poder significante de la individualidad de las esculturas.

La obra de Becky Guttin es una de las más enriquecedoras de la estética de la escultura mexicana actual. Se advierte claramente que la decidida artisticidad de esa producción no se dejaría moldear por la influencia de pedigüeñas exigencias que no provinieran de la indagación en la materia y en el espacio mismos, o que no se lo demandaran sus propias "necesidades sígnicas"6 (la expresión, el contenido y todos los recursos estéticos que estructuran una obra).

6. Alberto Hijar, "Lecciones escultóricas", en Salón Nacional de Artes Plásticas. Sección Trienal de Escultura 1985, México, Instituto Nacional de Bellas Artes, 1985, s.n., ils. 
La aportación más sustanciosa de la artista hoy día es su planteamiento compositivo y estructural a partir de la oposición, fenómeno en el que siempre palpita, como sustrato potencial, otra manera de continuidad, coincidencia y acoplamiento de dos o más dimensiones.

La oposición va en pos de otras armonías de ruptura con lo dispuesto por la simetría y el equilibrio entendidos como balances exactos, bilateralmente iguales, cuyas partes convergen con precisión.

En algunos momentos de su producción, Becky Guttin llega a la invocación de lo orgánico no porque lo imite, sino porque, contrariamente - en lúcido proceso-, ello surge del trabajo riguroso de mutación, metamorfosis y transformación técnica de la materia. Esa elaboración se ve orientada por las ideas, las sensaciones y la voluntad hermanadas en sistemas serena o violentamente proclives a lo multiformal entre el orden y el naufragio.

La otra cualidad de la obra de Becky Guttin es su texturalidad. Esto la hace mirar hacia la familia de los Pomodoro, los Noguchi, los Chillida, por ejemplo. Del pasado, a los Dubuffet, maestros con los que ella guarda, lo hemos visto, profundas coincidencias que aún prodigarán obras cada vez más y más maduras en su infatigable experimentación. Las ya realizadas denotan que la autora ha comenzado a rozar el centro de su emoción y a bien traducir a voluntad y hacer escultóricos el potencial de sus ideas.

La poética y valor plástico de las esculturas de Guttin brotan de la oposición, la contradicción formal, textural, cromática y, por lo tanto, de la tensión y la ruptura, dimensiones no distantes, según Alberto Híjar, de un intento humanizador: "Los filos cristalinos y metálicos, los destellos y las opacidades no sólo son físicos, sino también culturales y hasta éticos. Plantean al trabajo artístico como ruptura de límites materiales a fin de liberarlos del reduccionismo utilitarista." 7

\section{Bibliografia}

Acha, Juan, "Las dificultades del escultor", en 3 dimensiones, 20 expresiones. Catálogo de exposición, México, Museo de Arte Modeıno, 1988

Híjar, Alberto, "Lecciones escultóricas", en Salón Nacional de Artes de Artes Plásticas. Secioion Trienal de Escultura 1985. México, Instituto Nacional de Bellas Artes, I985.

7. Alberto Híjar, "Intersecciones, rupturas, transgresiones", nota de presentación de la muestra que Guttin exhibió en febreto de 1994 en el Instituto José María Luis Mora. 